\title{
Why are East Asian ecosystems important for carbon cycle research?
}

\author{
FANG JingYun ${ }^{1 *}$, TANG YanHong ${ }^{2} \&$ SON Yowhan ${ }^{3}$ \\ ${ }^{1}$ Department of Ecology, Key Laboratory for Earth Surface Processes of the Ministry of Education, Peking University, \\ Beijing 100871, China; \\ ${ }^{2}$ National Institute for Environmental Studies, Onogawa 16-2, Tsukuba 305-8506, Japan; \\ ${ }^{3}$ Division of Environmental Science and Ecological Engineering, Korea University, Seoul 136-713, Korea
}

Received June 30, 2010; accepted July 2, 2010

Citation: Fang J Y, Tang Y H, Son Y. Why are East Asian ecosystems important for carbon cycle research. Sci China Life Sci, 2010, 53: 753-756, doi: $10.1007 / \mathrm{s} 11427-010-4032-2$

The global carbon cycle is one of the most important biogeochemical cycles. Through photosynthesis, green plants absorb $\mathrm{CO}_{2}$ from the atmosphere to produce organic matters, such as sugars, and covert solar energy into chemical energy. The organic matters are then used by all other life forms including humans. When ecosystems and atmosphere are in dynamic equilibrium, the flow of $\mathrm{CO}_{2}$ from the atmosphere into the biosphere because of photosynthesis should be equivalent to the flow of $\mathrm{CO}_{2}$ released back into the atmosphere by respiration. However, during the past century atmospheric $\mathrm{CO}_{2}$ concentration has increased substantially because of the burning of fossil fuels. It is highly likely that the atmospheric increase has resulted in global warming and sea level rise, as suggested by the Intergovernmental Panel on Climate Change (IPCC) [1].

Although it is widely accepted that anthropogenic $\mathrm{CO}_{2}$ is the main source of increased atmospheric $\mathrm{CO}_{2}$ concentrations, the rates of atmospheric $\mathrm{CO}_{2}$ increase are substantially lower than those of anthropogenic emissions, and there are no parallel oscillations between the increase in atmospheric $\mathrm{CO}_{2}$ concentration and anthropogenic emissions of $\mathrm{CO}_{2}$ on annual time scale [2]. The magnitude and interannual fluctuations of terrestrial and marine carbon sinks may contribute primarily to these discrepancies. Since the 1970's, this discrepancy has been termed the "mystery of missing carbon sink" in the global carbon cycle [3-5], and has attracted scientists from different disciplines to at-

*Corresponding author (email: jyfang@urban.pku.edu.cn) tempt to solve the mystery [6,7].

Recent studies have shown that more than half of anthropogenic $\mathrm{CO}_{2}$ is sequestered by terrestrial and marine ecosystems. However, little is known about its amount, distribution, and inter-annual fluctuations. Some studies further suggested that compared with the oceans, terrestrial ecosystems are the major source of uncertainties in the global carbon cycle because of their larger spatial heterogeneity $[8,9]$ (Figure 1).

Quantifying the spatiotemporal uncertainties in terrestrial carbon sinks has become a critical issue in the study of the global carbon cycle, and detailed assessment of regional land carbon sinks/sources is the basis for understanding carbon cycle intensity, processes and mechanisms. During the past few decades, tremendous efforts have been made toward investigating terrestrial carbon exchange to meet the increasing needs of both science communities and policymakers. Several key regional programs such as the North American Carbon Program (NACP), Carbon Europe Integrated Project (Carbo Europe) and African carbon project (Carbo Africa) have been established to clarify regional carbon budgets. These programs have been greatly contributing knowledge of the carbon cycle in their respective regions (http://www.globalcarbonproject.org/carbontrends).

East Asia, located at the eastern margin of the Eurasian Continent and the western coast of the Pacific Ocean, covers $11760000 \mathrm{~km}^{2}$ and has a population of more than 1.5 billion. This area includes five nations: China, Japan, South Korea, North Korea, and Mongolia. Compared with other 

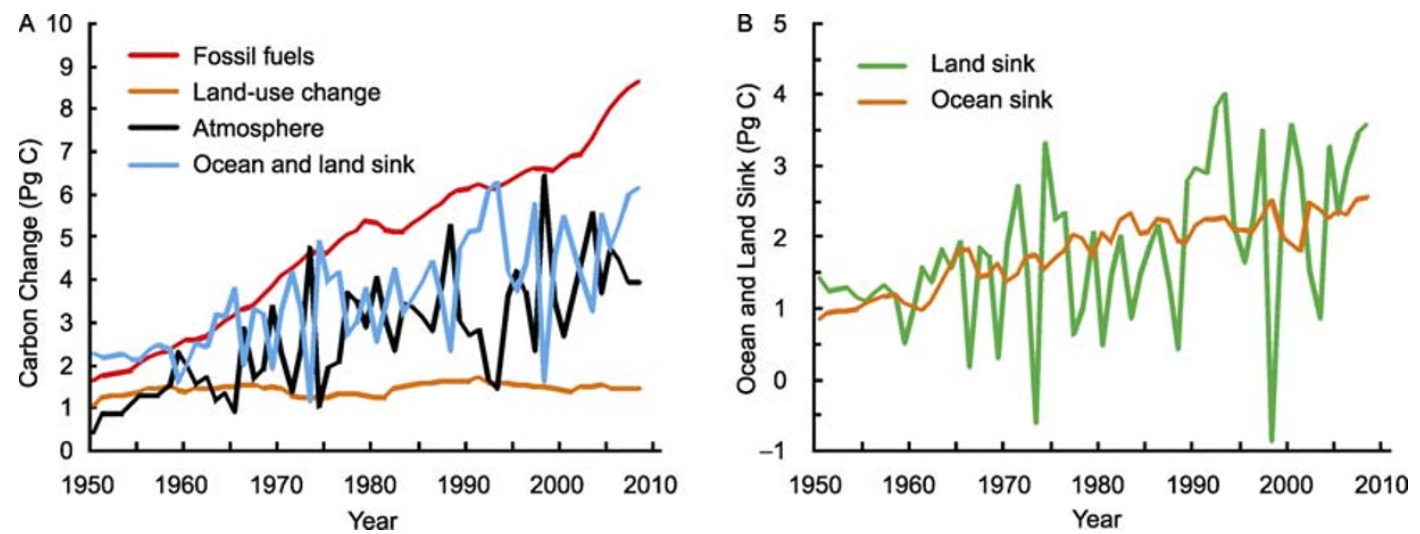

Figure 1 Changes in the components of the global carbon fluxes. A, Mass of carbon emitted from fossil fuel combustion and land-use change, retained in the atmosphere, and sequestered in oceans and on land; B, interannual changes in ocean and land carbon sinks, showing much smaller fluctuations in the former than in the later. Data are from refs. [8,9] and Fang (2009, unpublished data).

continents such as Europe and North America, East Asia may have more ecological importance in the study of global carbon cycle. This is not only because of a wide range of climates and diversity of species and ecosystems, which provide a model for exploring the heterogeneity of ecological attributes of carbon circulation, but also because of its high population densities, which can provide insight into our understanding of anthropogenic impacts on ecosystem structures and functions. However, carbon cycle studies in East Asia have been poorly conducted, and thus international collaboration in the region is needed, such as those found in European and North American programs.

Consequently, the A3 Foresight Program was launched in 2007 , funded by the national foundations of three countries of East Asia; the National Natural Science Foundation of China (NSFC), the Japan Society for the Promotion of Science (JSPS) and the South Korea's National Research Foundation (NRF). The project aimed to understand magnitude, distribution and mechanisms of carbon cycle in East Asia. During the past 3 years, through the consistent effort of all the participants, the project has achieved significant progresses in both science and communications [10,11].

Assessing potentials of terrestrial carbon sinks and predicting their future changes in East Asia are of great importance, both to understand scientifically and in developing strategies for terrestrial carbon management in the region.

First, East Asia is the major region influenced by the Asian monsoon and has been considered one of the most critical and sensitive regions in the global climate system [12]. For example, over the past two decades mean annual temperature in China has increased by approximately $1{ }^{\circ} \mathrm{C}$, higher than that of average global increases [13,14]. Precipitation patterns have also changed significantly [13]. These climate changes could significantly alter ecosystem processes, thereby influencing the regional carbon cycle.

Second, East Asia has almost all climate types in the world (Figure 2). This diversity provides a unique platform to examine the interactions between climate and ecosystem responses in terms of carbon dynamics.

Third, East Asia has very high population density, with more than $21 \%$ of the world population inhabiting less than $8 \%$ of the global terrestrial area. The strong impacts of human activities on terrestrial ecosystems has led to substantial carbon cycle changes, especially in soil carbon stocks, with probable impacts on climate systems [15]. This makes the region a unique for understanding the effects of land use change on the carbon cycle.

Fourth, over the past several decades East Asia has experienced extensive forestation and reforestation, which has made the forests the significant carbon sinks [16-18]. On the other hand, for individual countries and whole the region, vegetation cover as indicated by satellite indices did not show significant increases, and in the last 10 years vegetation cover in Japan and South Korea has in fact decreased (Figure 3 ). The effects of such changes on carbon cycles have been studied in each country, but no integrated scientific program has been initiated to assess the magnitude and changes of carbon sinks in the region.

Fifth, East Asia has become one of the most active regions in the global economy and experienced rapid industrialization and urbanization. This has led to the emission of billions of tons of $\mathrm{CO}_{2}$ into the atmosphere because of the consumption of huge amounts of fossil fuels and cement production. Thus, the region has an important role in modulating the carbon cycle at both the regional and global scales, and has accordingly received much attention from a global perspective. Understanding such impacts on the atmospheric system induced by human activities is a critical issue in the study of global changes.

Finally, the diversity of regional political regimes and economic structure poses a challenge to scientific implementation. East Asia includes highly-developed nations such as Japan and South Korea, relatively poorly developed nations like Mongolia and North Korea, and rapidly developing transitional nations like China. Interestingly, these seem to be a good correlation between economic develop- 
ment and carbon budgets. Initially, high rates of $\mathrm{CO}_{2}$ emissions are accompanied by fast industrialization and urbanization. After this period, vegetation recovers rapidly and the region often functions as a carbon sink. We can call this coevolution of society and nature the "ecological transition". This transition first appeared in Japan in about 1950, then in South Korea (1960-1970), and lastly in China (1980). We can expect that "ecological transition" will appear in North Korea and Mongolia in the near future. In other words, the timing of the ecological transition is related closely to transition in economic structure. Such an idea seems inconsistent with the commonly held notion that economic development inevitably results in deterioration of natural environments. In this sense, "ecological transition" is an interesting and pertinent topic in studying the carbon cycle in East Asia.

In response to the above-mentioned needs for research, we commenced a joint research project in 2007, aiming to characterize the magnitude, distribution and underlying mechanisms of carbon sources and sinks in East Asia. Our particular focus is the relationships between the carbon cycle and anthropogenic factors. This special issue reflects in part outcomes from this research program.

This special issue contains 14 contributions categorized into 4 parts. The first part consists of 4 review papers on carbon stocks and their regional variations. Fang et al. [23] examines the carbon balance of grasslands in China, and concludes that China's grasslands acted as a neutral carbon sink. Huang et al. [24] reviews soil carbon stocks and changes in China, and found that China's carbon stocks were increasing overall. In a data synthesis by Xu et al. [25],

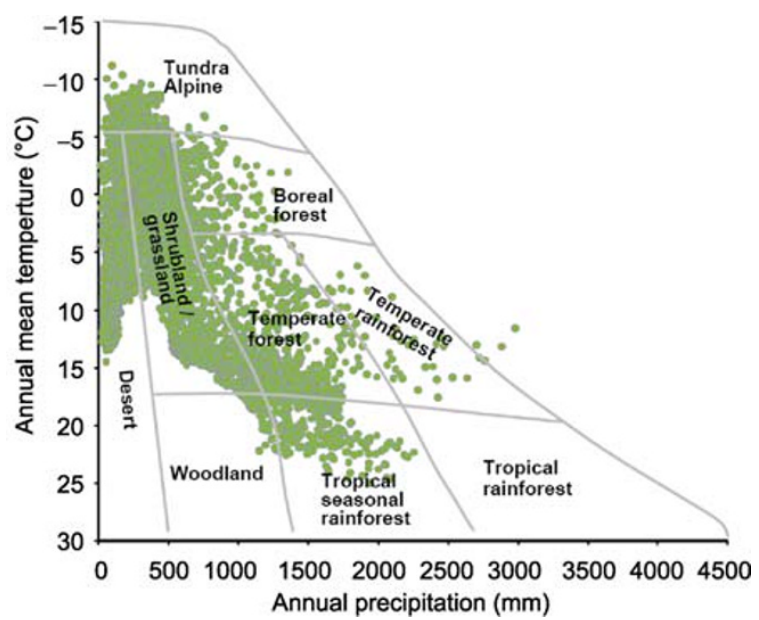

Figure 2 East Asian biomes presented in relation to world biomes. The world biomes defined according to annual mean temperature and precipitation are derived from Whittaker [19]. Each point represents an average with $0.5^{\circ} \times 0.5^{\circ}$ latitude / longitude grid cell. East Asia possesses almost all major world biomes; however, occurrences of tropical rainforests on Hainan Island, the southern margin of the Himalayas, southern Yunnan Province and southern Taiwan are not indicated in the figure because of their small individual areas.

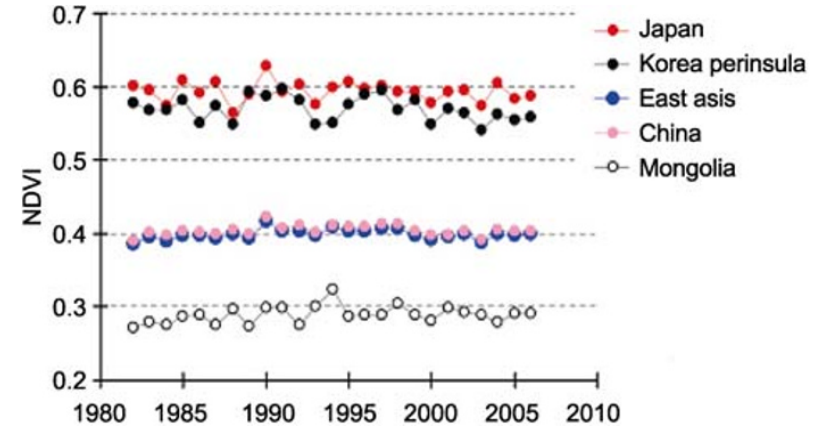

Figure 3 Interannual variation in growing season NDVI (Normalized Difference Vegetation Index) for the East Asian region as a whole, and each individual major region (China, Japan, Mongolia and the Korean Peninsula) from 1982 to 2006 . The growing season NDVI did not show a significant change across the region over the period shown $\left(R^{2}<0.1, P>0.1\right)$. Corresponding to precipitation and forest coverage, the average NDVI value decreased in the order: Japan $>$ Korea $>$ China $>$ Mongolia. The entire East Asian region showed a similar averaged NDVI to that of China. NDVI data were obtained from $8 \mathrm{~km} \times 8 \mathrm{~km}$ NOAA-AVHRR data [20-22]. To eliminate the effects of desert areas, grid cells with annual average NDVI $<$ 0.1 were not used in the analysis.

they suggest that forests in China will act as a large carbon sink over the next 50 years. Choi et al. [26] conducts a simulation study on changing vegetation pattern in Korean forests in relation to climate changes. Part 2 of the issue reports changes in carbon sources and sinks for different forest ecosystems including tropical monsoon rainforests [27], subtropical evergreen broad-leaved forests [28] and temperate forests $[29,30]$. Part 3 includes four contributions addressing carbon stocks and changes in grassland and farmland ecosystems. Ma et al. [31] examines biomass changes over the last 25 years in grasslands in northern China. Wang et al. [32] analyzes the spatial distribution of above/under-ground biomass in a temperate grassland. Wang et al. [33] investigates farmland surface soil organic carbon dynamics in China, based on a long-term fertilization dataset. Qin et al. [34] simulates carbon sequestration potential of farmlands in China. Part 4 presents two contributions from Korea focusing on new approaches to carbon cycle research. Kim et al. [35] uses aerial photography and Kwak et al. [36] uses LiDAR data to estimate changes in biomass/carbon stocks and leaf area in Korean forests.

This issue was funded mainly by the A3 Foresight Program, which was co-supported by NSFC in China, JSPS in Japan, and NRF in Korea. The principal investigators from the three countries are Professor Fang JingYun (Peking University), Professor Muraoka Hiroyuki (Gifu University), and Professor Son Yowhan (Korea University), respectively. We would like to extend our many thanks to Wang ShaoPeng, Zhu JiangLing, Yue Chao and Zhao Xia for help in data processing and words proofreading. Without the kind help of Professor Wang DaCheng, the Editor-in-Chief of Science China Life Sciences, and the editorial office staff, this special issue would not have been possible. 
1 IPCC. Climate Change 2007: The Physical Science Basis. Contribution of Working Group I to the Fourth Assessment Report of the Intergovernmental Panel on Climate Change. Cambridge: Cambridge University Press, 2007. 241-253

2 Le Quéré C, Raupach M R, Canadell J G, et al. Trends in the sources and sinks of carbon dioxide. Nat Geosci, 2009, 2: 831-836

3 Reiners W A. A summary of the world carbon cycle and recommendations for critical research. In: Woodwell G M, Pecan E V, eds. Carbon and the Biosphere. AEC Symposium Series, 1973, 30: 368382. NTIS U.S. Department of Commerce, Springfield, Virginia.

4 Bolin B. Changes of land biota and their importance for the carbon cycle. Science, 1977, 196: 613-615

5 Woodwell G M, Whittacker R H, Reiners W A, et al. The biota and the world carbon budget. Science, 1978, 199: 141-146

6 Fang J Y. Seeking the missing carbon sinks. Acta Phytoecol Sin, 2002, 26: 255-256

7 Fang J Y, Piao S L, Zhao S Q. The carbon sink: the role of the middle and high latitudes terrestrial ecosystems in the Northern Hemisphere. Acta Phytoecol Sin, 2001, 25: 594-602

8 Canadell J G, Le Quéré C, Raupach M R et al. Contributions to accelerating atmospheric $\mathrm{CO}_{2}$ growth from economic activity, carbon intensity, and efficiency of natural sinks. Proc Natl Acad Sci USA, 2007, 104: 18866-18870

9 Oak Ridge National Laboratory. http://cdiac.ornl.gov/trends/emis/ meth_reg.html, 2008

10 Fang J Y, Guo Z D, Piao S L, et al. Terrestrial vegetation carbon sinks in China, 1981-2000. Sci China Ser D-Earth Sci, 2007, 50: 1341-1350

11 Piao S L, Fang J L, Ciais P, et al. The carbon balance of terrestrial ecosystems in China. Nature, 2009, 458: 1009-1013

12 Fu C, Penning de Vries FWT, Ailikun, et al., eds. The initial Science Plan of the Monsoon Asia Integrated Regional Study. Beijing: China Meteorological Press, 2006

13 Editorial Board of "National assessment report on climate change". National Assessment Report on Climate Change. Beijing: Science Press, 2007

14 Wang S P, Wang Z H, Piao S L, et al. Regional differences in the timing of recent air warming during the past four decades in China. Chinese Sci Bull, 2010, 55, doi: 10.1007/s11434-010-3236-y

15 Lal R. Soil carbon sequestration impacts on global climate change and food security. Science, 2004, 304: 1623-1627

16 Fang J Y, Chen A P, Peng C H, et al. Changes in forest biomass carbon storage in China between 1949 and 1998. Science, 2001, 292: 2320-2322

17 Fang J Y, Oikawa T, Kato T, et al. Biomass carbon accumulation by Japan's forests from 1947-1995. Glob Biogeochem Cyc, 2005, 19, GB2004, doi:10.1029/2004GB002253

18 Choi S D, Lee K, Chang Y S. Large rate of uptake of atmospheric carbon dioxide by planted forest biomass in Korea. Glob Biogeochem Cyc, 2002, 16: Art. No. 1089

19 Whittaker R. Communities and Ecosystems. New York: MacMillan, 1975. 1-167
20 Zhou L M, Tucker C J, Kaufmann R K, et al. Variations in northern vegetation activity inferred from satellite data of vegetation index during 1981 to 1999. J Geophys Res, 2001, 106: 20069-20083

21 Piao S L, Fang J Y, Zhou L M, et al. Interannual variations of monthly and seasonal normalized difference vegetation index (NDVI) in China from 1982 to 1999. J Geophys Res-Atmos, 2003, 108: 4401, doi:10.1029/2002JD002848

22 Fang J Y, Piao S L, He J S, et al. Increasing terrestrial vegetation activity in China, 1982-1999. Sci China Ser-C Life Sci, 2004, 47: 229-240

23 Fang J Y, Yang Y H, Ma W H, et al. Ecosystem carbon stocks and their changes in China's grasslands. Sci China Life Sci, 2010, 53: 757-765

24 Huang Y, Sun W J, Zhang W, et al. Changes in soil organic carbon of terrestrial ecosystems in China: A mini-review. Sci China Life Sci, 2010, 53: 766-775

$25 \mathrm{Xu} \mathrm{B}$, Guo Z D, Piao S L, et al. Biomass carbon stocks in China's forests between 2000 and 2050: a prediction based on forest biomass-age relationships. Sci China Life Sci, 2010, 53: 776-783

26 Choi S, Lee W-K, Son Y, et al. Changes in the distribution of South Korean forest vegetation simulated using thermal gradient indices. Sci China Life Sci, 2010, 53: 784-797

27 Chen D X, Li Y D, Liu H P, et al. Biomass and carbon dynamics of a tropical mountain rain forest in China. Sci China Life Sci, 2010, 53: 798-810

28 Yang T H, Song K, Da L J, et al. The biomass and aboveground net primary productivity of Schima superba-Castanopsis carlesii forests in east China. Sci China Life Sci, 2010, 53: 811-821

29 Noh N J, Son Y H, Lee S K, et al. Carbon and nitrogen storage in an age-sequence of Pinus densiflora stands in Korea. Sci China Life Sci, 2010, 53: 822-830

30 Zhang Q Z, Wang C K, et al. Carbon density and distribution of six Chinese temperate forests. Sci China Life Sci, 2010, 53: 831-840

31 Ma W H, Fang J Y, Yang Y H, et al. Biomass carbon stocks and their changes in northern China's grasslands during 1982-2006. Sci China Life Sci, 2010, 53: 841-850

32 Wang L, Niu K C, Yang Y H, et al. Patterns of above- and belowground biomass allocation in China's grasslands: Evidence from individual-level observations. Sci China Life Sci, 2010, 53: 851-857

33 Wang C J, Pan G X, Tian Y G, et al. Changes in cropland topsoil organic carbon with different fertilizations under long-term agroecosystem experiments across mainland China. Sci China Life Sci, 2010, 53: 858-867

34 Qin Z C, Huang Y. Quantification of soil organic carbon sequestration potential in cropland: A model approach. Sci China Life Sci, 2010, 53: 868-884

35 Kim S-R, Kwak D-A, Lee W-K, et al. Estimation of carbon storage based on individual tree detection in Pinus densiflora stands using a fusion of aerial photography and LiDAR data. Sci China Life Sci, 2010, 53: 885-897

36 Kwak D-A, Lee W-K, Kafatos M, et al. Estimation of effective plant area index for South Korean forests using LiDAR system. Sci China Life Sci, 2010, 53: 898-908 